\title{
Sweet's syndrome: histological and immunohistochemical study of 15 cases
}

\author{
J J GOING, S M GOING,* M W MYŚKOẂ, G W BEVERIDGE* \\ From the Department of Pathology, Edinburgh University Medical School, Edinburgh, and *University \\ Department of Dermatology, The Royal Infirmary, Edinburgh, Scotland
}

SUMMARY Conventional histology and immunoperoxidase staining for fibrin, immunoglobulins, and complement components were used to look for evidence of cutaneous vasculitis and immune complex deposition in Sweet's syndrome. These features were not identified in any of the 15 cases studied. The lack of any vasculitis emphasises the distinctive character of Sweet's syndrome when compared with certain spontaneous and experimentally induced inflammatory skin lesions, and may imply a similarly distinctive pathogenesis.

In 1964 RD Sweet described a new syndrome, "acute febrile neutrophilic dermatosis". 1 This disorder (AFND or Sweet's syndrome) has striking clinical and pathological features. The patient, usually female, develops tender, circumscribed, raised erythematous plaques, which most often occur on the face, neck, and arms. Rapid enlargement of these lesions may occur, with fever, neutrophilia, and a raised erythrocyte sedimentation rate. The impression of an acute infective process may be very strong, but no pathogens have ever been isolated, and if spontaneous resolution does not occur there is a rapid response to systemic treatment with steroids. Skin biopsy shows a heavy inflammatory infiltrate, mostly neutrophilic with some mononuclear cells, and pronounced oedema of the papillary dermis. It has been said that vasculitis is not a feature, and tissue necrosis and ulceration are rarely, if ever, seen in true Sweet's syndrome. ${ }^{2}$

The aetiology and pathogenesis of Sweet's syndrome remain unknown, but several cases have been reported in association with other illnesses: most importantly, about $10 \%$ of patients either have, or go on to develop, an acute leukaemia, usually of monocytic or myelomonocytic type. ${ }^{34}$ This is of interest in that leukaemic patients may develop pyoderma gangrenosum, a lesion characterised by intense neutrophilic infiltration of the dermis; Sweet's syndrome has been described in a patient with ulcerative colitis and pyoderma gangrenosum. ${ }^{5}$ Sweet's syndrome also shows histological similarities with erythema nodosum leprosum and, in experimental lesions, with the Shwartzman and Arthus reactions. ${ }^{67}$ As vasculitis and tissue necrosis may be observed in all these conditions it is worth while knowing if vasculitis and necrosis do occur in Sweet's syndrome. In view of its apparent immunological pathogenesis we looked for evidence of immune complex deposition in the skin. Because oedema exclusively affecting the papillary dermis is a feature of some delayed type hypersensitivity reactions, in which basophils may play a part (analogous to the cutaneous basophil hypersensitivity or "Jones-Mote" reaction of guinea pigs), ${ }^{8}$ stains for basophils and mast cells were performed.

\section{Material and methods}

Seventeen skin biopsy specimens from 15 patients with Sweet's syndrome seen in Edinburgh between 1975 and 1984 were examined. The diagnosis was made on combined clinical and histological grounds. The paraffin blocks of all specimens were obtained, recut, and four micron sections stained by the following methods: haematoxylin and eosin, periodic acid Schiff, toluidine blue, Perls's Prussian blue reaction, Masson trichrome, reticulin, Martius scarlet blue,

Table 1 Primary antisera and dilutions used for immunostaining

\begin{tabular}{ll}
\hline Antibody directed against: & Dilution \\
\hline Fibrin & $1 / 1000$ \\
IgA & $1 / 400$ \\
IgG & $1 / 1000$ \\
IgM & $1 / 400$ \\
$\kappa$ chains & $1 / 1000$ \\
$\lambda$ chains & $1 / 1000$ \\
$C 3$ & $1 / 100$ \\
C4 & $1 / 100$ \\
\hline
\end{tabular}


Table 2 Clinical data of cases studied

\begin{tabular}{|c|c|c|c|c|c|c|c|}
\hline Case & Age & Sex & $\begin{array}{l}\text { White cell count } \\
\left(10^{9} / l\right)\end{array}$ & $\begin{array}{l}\text { Neutrophils } \\
(\%)\end{array}$ & $\begin{array}{l}\text { Distribution } \\
\text { of rash }\end{array}$ & $\begin{array}{l}\text { Non-cutaneous } \\
\text { manifestations }\end{array}$ & Other \\
\hline 1 & 36 & $\mathrm{~F}$ & 8 & & & & \\
\hline 2 & 56 & $\mathbf{M}$ & $5 \cdot 2$ & & Hand, cheek, neck & & \\
\hline 3 & 62 & $\mathrm{~F}$ & $15 \cdot 6$ & 68 & Arms & & Iritis; inactive breast cancer \\
\hline 4 & 73 & $\mathrm{~F}$ & & & Arms, face & & \\
\hline 5 & 62 & $\mathbf{M}$ & $12 \cdot 7$ & 80 & Hands, arms, face & Conjunctivitis & \\
\hline 6 & 59 & $\mathrm{~F}$ & $9 \cdot 2$ & 82 & Arms, legs & & $\begin{array}{l}\text { Lymphoma; mesangiocapillary } \\
\text { glomerulonephritis }\end{array}$ \\
\hline 7 & 30 & $\mathbf{F}$ & $10 \cdot 0$ & & Hands, cheeks & & \\
\hline 8 & 64 & $\mathrm{~F}$ & $14 \cdot 3$ & 78 & Arms, legs & Arthralgia & \\
\hline 9 & 60 & $F$ & $18 \cdot 5$ & 53 & Arms & Night sweats & $\begin{array}{l}\text { Seronegative rheumatoid arthritis; } \\
\text { later acute myeloid leukaemia }\end{array}$ \\
\hline 10 & 50 & $\mathbf{M}$ & $16 \cdot 1$ & 80 & Arms, legs & Arthralgia & Psoriasis \\
\hline 11 & 72 & $\mathrm{~F}$ & $9 \cdot 3$ & 84 & Arms & $\begin{array}{l}\text { Arthralgia, } \\
\text { conjunctivitis }\end{array}$ & \\
\hline 12 & 76 & $\mathbf{F}$ & $10 \cdot 7$ & 70 & Arms, face, legs & & $\begin{array}{l}12 \text { years of benign monoclonal } \\
\text { gammopathy; acute pancreatitis }\end{array}$ \\
\hline 13 & 34 & $\mathbf{F}$ & $13 \cdot 1$ & 62 & Face, chest & $\begin{array}{c}\text { Periorbital } \\
\text { oedema }\end{array}$ & 16 weeks pregnant \\
\hline $\begin{array}{l}14 \\
15\end{array}$ & $\begin{array}{l}39 \\
22\end{array}$ & $\mathbf{F}$ & 10.9 & 83 & $\begin{array}{l}\text { Arms, legs } \\
\text { Face, neck }\end{array}$ & & \\
\hline
\end{tabular}

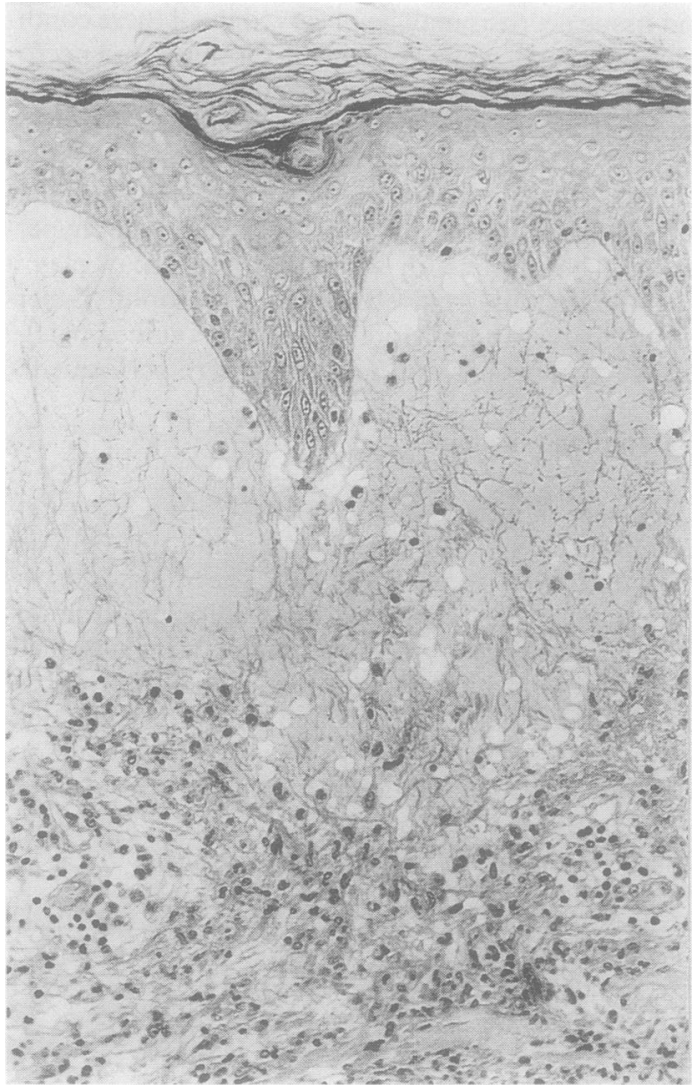

Fig 1 Case 5: pronounced oedema of papillary dermis raises intact epidermis and dense inflammatory infiltrate in deeper layers of the dermis. (Masson trichrome.) $\times 160$. and Giemsa. Sections dried at low temperature $\left(56^{\circ} \mathrm{C}\right)$ were stained by a three stage peroxidase and immunoperoxidase technique using commercially supplied rabbit polyclonal antibodies (Dako) (table 1). All sections were trypsinised for 15 minutes before staining, using $0 \cdot 1 \%$ trypsin in $0 \cdot 1 \%$ calcium chloride at a $\mathrm{pH}$ of $7 \cdot 6$ to $7 \cdot 8$.

\section{Results}

Table 2 summarises the clinical details of the 15

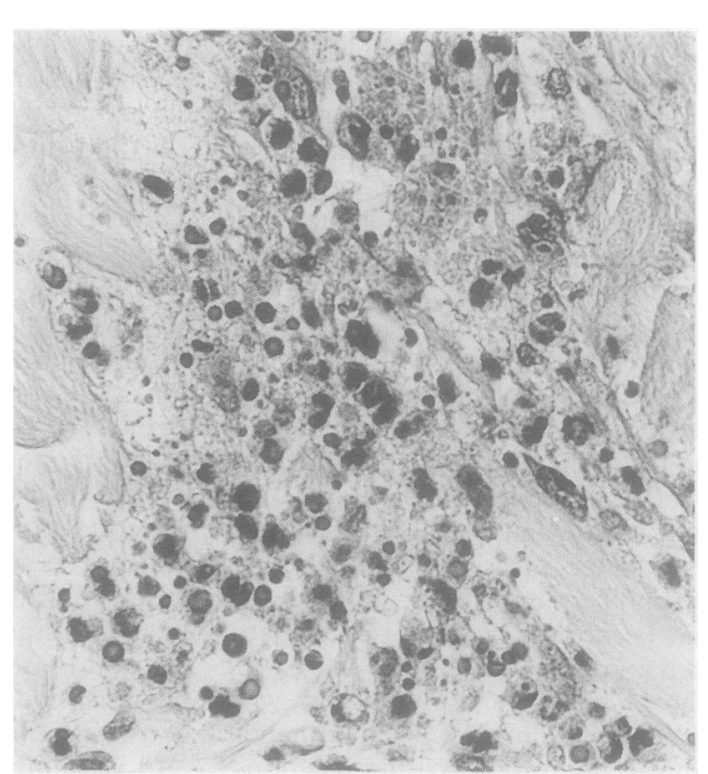

Fig 2 Case 12: conspicuous neutrophilic dermal infitrate

with leucocytoclasis. (Masson trichrome.) $\times 500$. 


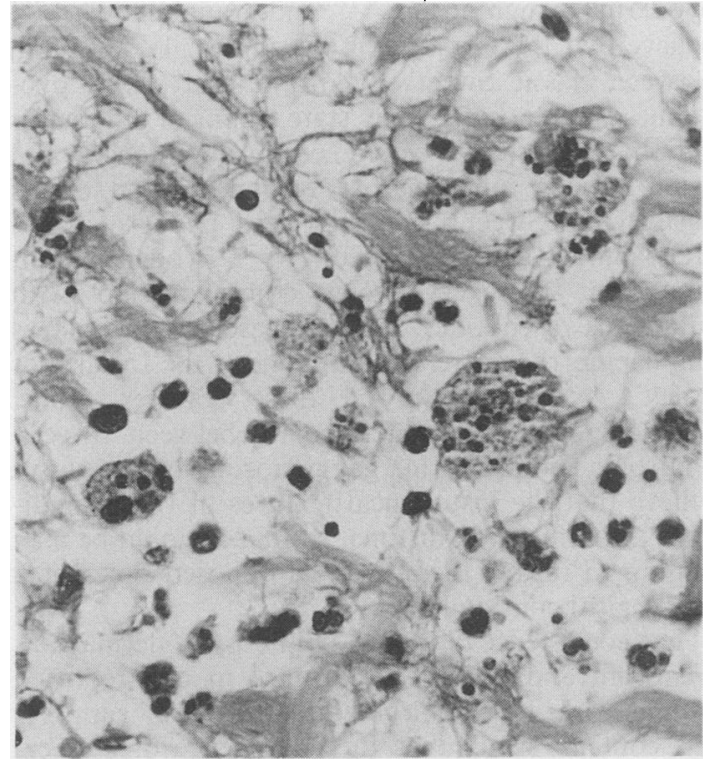

Fig 3 Case 2: neutrophil nuclear debris ingested by macrophages. (Haematoxylin and eosin.) $\times 500$.

patients. The female preponderance (12 of 15$)$ was typical, as was the often pronounced neutrophilia, the distribution of the rash, and the arthralgia and conjunctivitis seen in some cases. Other patients experienced a range of medical problems, but only two patients (cases 6 and 12) had new illnesses diagnosed at the same time as Sweet's syndrome. One patient (case 6) presented with Sweet's syndrome; lymphadenopathy due to a B cell lymphoma was found and she subsequently developed mesangiocapillary glomerulonephritis. The second patient (case 12) developed acute pancreatitis, followed, after a day or two, by Sweet's syndrome: another patient (case 9) developed acute myeloid leukaemia one year after Sweet's syndrome; and another (case 13) was 16 weeks pregnant.

Body temperature was not consistently recorded but was raised $\left(38 \cdot 5-40^{\circ} \mathrm{C}\right)$ in those cases where a record existed.

\section{HISTOLOGY}

The epidermis showed only minor changes. Mild to moderate spongiosis was common: spongiotic vesicles can form. The basement membrane was intact and at most a very few inflammatory cells had entered the basal layers. Some flattening of the rete ridges was seen, and keratinisation was usually unaffected. Epidermal necrosis and ulceration were not seen.

The papillary dermis typically showed a striking oedema, which may be so severe that the epidermis seems to be held down by a few attenuated strands of

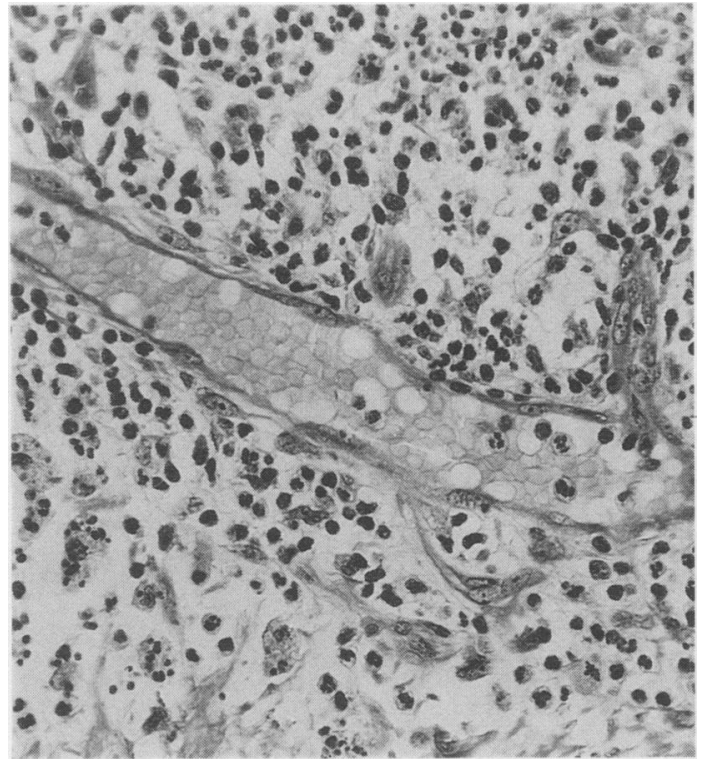

Fig 4 Case 2: this small dermal vessel shows no evidence of vasculitis. (Haematoxylin and eosin.) $\times 320$.

collagen only (fig 1). A subepidermal bulla may be simulated, but close inspection will always show some connective tissue elements spanning the apparent cleft. A pale homogeneous eosinophilic background suggests that the fluid is a proteinaceous exudate, in keeping with the inflammatory nature of the lesion. The junction with the reticular dermis tends to be sharply defined, with little oedema in the deeper levels. Dilated capillaries lined by plump endothelial cells may be conspicuous at the junction, and some may run upwards into the oedematous reticular dermis. Occasional mitotic figures among the endothelial cells of these capillaries suggest reparative activity or new vessel formation.

There was a diffuse, heavy, inflammatory infiltrate in the reticular dermis; usually neutrophils predominate and nuclear fragments (leucocytoclasis) may be conspicuous (fig 2). Eosinophils in small numbers are sometimes seen, and lymphocytes and histiocytes are always present, sometimes outnumbering the neutrophils. Ingestion of nuclear fragments by histiocytes is conspicuous in some cases (fig 3 ). The inflammatory infiltrate is usually heaviest in the mid dermis but may extend into the subcutaneous fat, although none of our cases showed conspicuous panniculitis.

Examination of the dermal blood vessels showed that vasculitic changes (thrombosis, fibrinoid necrosis, fibrin deposition, red cell extravasation, inflammatory infiltration of vascular walls) were absent in all cases (fig 4).

An attempt to relate the composition of the 


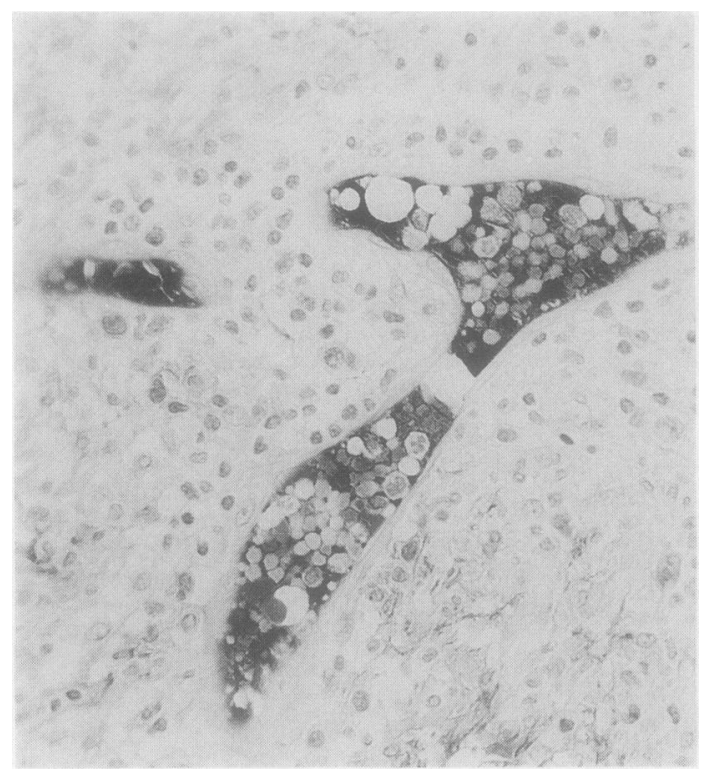

Fig 5 Case 8: this dermal vessel shows immunostaining for fibrin in lumen but no deposition in the intact vessel wall. (Immunoperoxidase.) $\times 160$

absent in all cases (fig 4).

An attempt to relate the composition of the inflammatory infiltrate to the age of the lesion biopsied was unsuccessful because accurate dating of biopsied lesions was not available. Although special fixatives were not used, and we may therefore have underestimated their numbers, basophils and mast cells were inconspicuous and it seems unlikely that they play a part in Sweet's syndrome.

\section{IMMUNOHISTOCHEMISTRY}

Staining with the antifibrin antibody showed fibrin within vascular lumina and the fluid in the oedematous papillary dermis, in keeping with the fact that this fluid is inflammatory exudate. Fibrin deposits were not present within vessel walls, confirming the absence of a vasculitis (fig 5). A similar pattern of staining occurred for immunoglobulin and complement components, but there was no deposition of reaction product in or around vessel walls.

\section{Discussion}

The aetiology and pathogenesis of Sweet's syndrome remain unclear. The absence of vasculitis is important in considering similarities with other cutaneous inflammatory syndromes. It has been suggested ${ }^{4}$ that Sweet's syndrome, at least when it occurs in association with leukaemia, is closely related to bullous pyoderma gangrenosum, ${ }^{910}$ and Caughman et al ${ }^{11}$ believe that there is a pathophysiological continuum between classic Sweet's syndrome and classic pyoderma gangrenosum. They state, "clinical differences may be attributed to differences in the intensity and extent of the inflammatory response," and others believe that Sweet's syndrome and pyoderma gangrenosum are closely related. ${ }^{101213}$ Pyoderma gangrenosum, however, shows some overlap with cutaneous vasculitides, and intravascular thrombosis and haemorrhage are typical. None of the 15 cases of Sweet's syndrome showed these features. Thus, although syndromes intermediate between Sweet's syndrome and pyoderma gangrenosum may exist, we believe that the histological features of these conditions are sufficiently distinct, so that it would be misleading to regard them even as opposed poles of a nosological continuum.

The coexistence of atypical bullous pyoderma gangrenosum and Sweet's syndrome ${ }^{8}$ in one reported patient with a myeloproliferative disorder supports this contention, as does the coexistence of atypical pyoderma gangrenosum and typical Sweet's syndrome in a patient with ulcerative colitis. ${ }^{5}$

The lack of evidence of immune complex deposition in the skin of our patients does not prove that deposition does not occur, as immunoperoxidase methods may not be sensitive enough to show minimal deposition, but it does seem unlikely that large complexes formed in conditions of antibody excess are being deposited.

To conclude, we would emphasise that Sweet's syndrome is not a cutaneous vasculitis, and intravascular thrombosis, tissue necrosis, and ulceration are not seen. There is no necessary connection with pyoderma gangrenosum and its variants.

We are grateful to $\mathrm{Mr}$ A Smith and Mr D Cossar for technical work, and to Mrs Carolyn Brown and Mrs Fiona Govan for preparing the manuscript.

\section{References}

1 Sweet RD. An acute febrile neutrophilic dermatosis. $\mathrm{Br} J \mathrm{Der}$ matol 1964;76:349-56.

2 Gunawardena DA, Gunawardena KA, Ratnayaka RMRS, Vasanthanathan NS. The clinical spectrum of Sweet's syndrome (acute febrile neutrophilic dermatosis) - a report of eighteen cases. Br J Dermatol 1975;92:363-73.

3 Matta M, Malak J, Tabet E, Kurban AK. Sweet's syndrome: systemic associations. Cutis 1973;12:561-5.

4 Cooper PH, Innes DJ, Greer KE. Acute febrile neutrophilic dermatosis (Sweet's syndrome) and myeloproliferative disorders. Cancer 1983;51:1518-26.

5 Benton EC, Rutherford D, Hunter JAA. Sweet's syndrome and pyoderma gangrenosum associated with ulcerative colitis. Acta Dermatol Venereol 1985;65:77-80.

6 Stetson CA, Good RA. Studies on the mechanism of the Shwartzman phenomenon. Evidence for the participation of poly- 
morphonuclear leucocytes in the phenomenon. $J$ Exp Med 1951;93:49-64.

7 Cochrane CG, Dixon RJ. Antigen-antibody complex induced disease. In: Meischer PA, Muller-Eberhard HJ, eds. Textbook of immunopathology. New York: Grune \& Stratton, 1976.

8 Dvorak HF, Mihm MC, Dvorak AM, et al. Morphology of delayed type hypersensitivity reactions in man. I. Quantitative description of the inflammatory response. Lab Invest 1974:31:111-30.

9 Perry HO, Winklemann RK. Bullous pyoderma gangrenosum and leukaemia. Arch Dermatol 1972;106:901-5.

10 Burton JL. Bullous pyoderma of leukaemia. Br J Dermatol 1976;95:209-10.

11 Caughman W, Stern R, Haynes H. Neutrophilic dermatosis of myeloproliferative disorders. J Am Acad Dermatol 1983; 9:751-8.

12 Pye RJ, Choudhury C. Bullous pyoderma as a presentation of acute leukaemia. Clin Exp Dermatol 1977;2:33-8.

13 Harrist TJ, Fine JD, Berman RS, et al. Neutrophilic eccrine hidradenitis: a distinctive type of neutrophilic dermatosis associated with myelogenous leukaemia and chemotherapy. Arch Dermatol 1982;118:263-6.

Requests for reprints to: Dr JJ Going, Department of Pathology, University Medical School, Teviot Place, Edinburgh EH8 9AG, Scotland. 